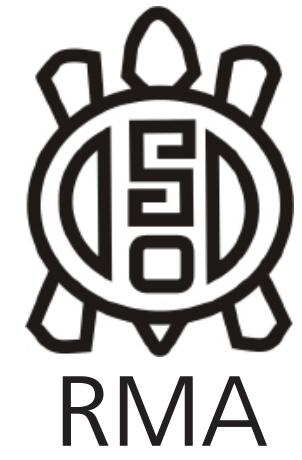

Antropología Social

\title{
Akuysh kichwaq guasapi yanasus. Repertorios bilingües quichua-castellano en redes virtuales de obreros migrantes santiagueños
}

\author{
Akuysh kichwaq guasapi yanasus. Virtual bilingual repertoires in \\ migrant workers of Santiago del Estero (Argentina)
}

\author{
Héctor Alfredo Andreani* \\ * Tecnicatura Superior en EIB mención Lengua Quichua, Universidad Nacional de \\ Santiago del Estero. E-mail: sachahector@gmail.com
}

\begin{abstract}
Resumen
A raíz de un trabajo etnográfico en una cuadrilla de obreros migrantes rurales de Santiago del Estero (Argentina), accedimos a un grupo de red social virtual. Desde una perspectiva en sociolingüistica etnográfica, este trabajo analiza determinados usos del repertorio bilingüe quichua-castellano desarrollados por los obreros "golondrina" (migrantes). Surgen nuevas interacciones bilingües referidas a gestiones ante organismos estatales, y otros temas vinculados con la masculinidad y la picardía, todos con base en una intensa explotación laboral. El análisis muestra que por fuera de la vinculación estereotipada entre la lengua quichua e ideologías lingüísticas generalizantes (basadas en factores familiares, folklóricos o culturales), aquí se vincula con una dimensión situada de clase, la cual reconfigura ámbitos previamente establecidos para desarrollar nuevos usos en estos obreros bilingües.
\end{abstract}

Palabras clave: Repertorio bilingüe; Obreros migrantes estacionales; Redes sociales virtuales; Explotación laboral.

\begin{abstract}
Starting from an ethnographic work between a group of rural migrant workers from Santiago del Estero (Argentina), we unexpectedly accessed a virtual social network group. From a perspective in ethnographic sociolinguistics, this paper analyzes the bilingual repertoire Quichua-Spanish developed by these migrant workers. There are new bilingual interactions related to negotiations with state agencies, and other issues related to masculinity and mischief, all based on intense labor exploitation. The analysis shows that outside the stereotyped link between the Quichua language and generalizing linguistic ideologies (based on family, folkloric or cultural factors), here it is linked to a class situated dimension, which reconfigures previously established areas to develop new uses in these bilingual workers.
\end{abstract}

Keywords: Bilingual repertoire; Seasonal migrant workers; Social media; Labor exploitation.

"no sé ni en qué momento ha aprendido, calculo que igual que yo, escuchando, pero he puesto en práctica la lengua en la desflorada. Ahí es donde uno pone en práctica la lengua, creo que es la primera prueba que uno tiene, de saber si habla quichua o no, entiende o no, quien se... Yo creo que el que se ha descubierto [quichuista, fue] ahí, al hablar en quichua (...) Entonces, yo cuando voy a la desflorada están todos varones y todos te hablan en, muchos te hablan en quichua o los más viejos te hablan en quichua, entonces [es] como una forma así de... de cancheriar, como una forma así también de participar de la conversación"". Sebastián, obrero golondrina.

Desde hace varias décadas en el imaginario social de Santiago del Estero (región del Noroeste argentino) hay ideologías profundamente cristalizadas sobre la variedad más sureña de la familia lingüística quechua, denominada localmente como "la quichua". Es un corpus de preconceptos que Voloshinov (1992 [1929]) describía como propios del subjetivismo lingüístico: desde la

Nota: Traducción del título en quichua: "Vamos a quichuar en el guasap [WhatsApp] amigos" 
asociación intensa entre lengua y folklore ${ }^{1}$, la delimitación a los usos quichuas al espacio familiar, la idea de que por ser categorizada localmente como "la quichua" sería una lengua de representación "femenina"2, o la niñez como receptáculo pasivo de la lengua considerada "materna". En el plano de las prácticas, es evidente que sí se han desarrollado de ese modo al interior de la lengua. Pero, por ejemplo, la idea "femenina" de la lengua suele reducirse a una concepción moralizante sobre un tipo de mujer anciana rural, hogareña, sumisa y "guardiana" del saber lingüístico. Siendo ideologías lingüísticas que operan como generalizaciones que sedimentan otros usos efectivos (cf. Gandulfo 2007: 131), nos interesa exponer que el cuadro general donde se asientan las prácticas lingüísticas endógenas no se agota allí.

Describiremos un ámbito muy diferente de usos bilingües referidos anteriormente. Se trata de obreros rurales migrantes estacionales llamados "golondrina", que son bilingües (quichua-castellano) y poseen un altísimo grado de subalternización cultural. El epígrafe con el discurso de Sebastián, un obrero migrante y quichuista ${ }^{3}$, permite introducirnos a un proceso sociolingüístico determinante, dada la proporción de población implicada y la intensidad de la práctica lingüística. A partir de una investigación entre 2010-2015, analizamos el repertorio bilingüe quichua-castellano desplegado en un grupo de What's App, compuesto exclusivamente por decenas de obreros rurales quichuistas.

Dado el aumento de la producción de semillas transgénicas que requieren trabajo manual fino, la asalarización y los vínculos duraderos con empresas tercerizadas, los jóvenes

\footnotetext{
1 La asociación es intensa porque el culturalismo nacionalista de mediados del siglo $X X$ impactó notoriamente el imaginario regional sobre la lengua, devenida en expresión folklórica exclusiva en determinados géneros musicales (chacarera, gato, vidala): desde el valor social atribuido a la obra musical folklórica del violinista bilingüe Sixto Palavecino (1915-2009), hasta el intenso sesgo folklórico de manuales de enseñanza de quichua destinados al nivel primario (Juárez de Paz, 1999; 2010). El proceso de folklorización de la lengua se cristaliza aún más en el presente siglo: desde el sostén estatal al discurso identitario folklórico y una estructura turística de relativa acumulación mediante un relato de neo-etnicidad provincial (Andreani 2016b), que refuerzan el estereotipo hegemónico sobre el quichua. Todos estos aspectos están parcial o totalmente disociados de las prácticas endógenas de los sectores bilingües.

2 Principalmente, la interpretación que Grosso (2008) toma de sus informantes de mediados de los 90.

3 Quichuista no refiere al monolingüe quichua, sino que es la categoría nativa para el bilingüe quichua-castellano, de modo muy similar en características al guaranisero correntino (Gandulfo 2007). Como estrategia históricamente situada (desde la década del 40 hasta hoy) el quichuista (bilingüe) se caracteriza por un uso lingüístico singular: el ocultamiento del quichua y el uso de los recursos que dispone del castellano para evitar marcaciones negativas (marginación) desde sector social representado en el castellano estándar, es decir, la mayoría poblacional configurada según los parámetros de la modernización estatal desde mediados del siglo XX hasta la actualidad. Por fuera de cualquier mitificación folklórica, intelectual o culturalista, la categoría nativa quichuista está inevitablemente atravesada por esta configuración estatal.
}

obreros "golondrina" han construido nuevas interacciones bilingües con otros obreros mediante la adquisición de dispositivos móviles. Esta fracción obrera forma parte de la inmensa sobrepoblación relativa conformada en la provincia desde mediados del siglo XX (Desalvo 2013). La sobrepoblación relativa o población sobrante es la fracción de la clase obrera que dicho capital no puede explotar productivamente, en términos de tiempo socialmente necesario (Kabat 2009).

Nuestro estudio se sitúa en la sociolingüística etnográfica, que se propone dar cuenta de los usos lingüísticos a través del análisis de datos relevados mediante técnicas etnográficas, con especial atención al estudio interaccional y discursivo de materiales empíricos (Heller, 2011; Codó, Patiño y Unamuno, 2012). Desde la perspectiva de Voloshinov, basamos nuestro problema de investigación observando la ideología subjetivista situada sobre el quichua: por fuera de generalizaciones basadas en la familia, la niñez, el feminización o la folklorización, describimos usos diferentes y muy frecuentes en una franja muy importante de hablantes. En este ambiente rige una producción de masculinidad (Palermo 2017) mediante mecanismos específicos de proletarización y productividad del trabajo (el "rinde" en el despanojamiento de maíz) en un contexto de empleo agrario multinacional. El chat de App no será aquí el objeto exclusivo, sino que lo utilizaremos como un cuerpo de indicios para ver cómo la dimensión situada de clase actualiza usos bilingües. En ese proceso, circulan nuevos temas, procedimientos y datos determinantes para el conocimiento práctico de sus integrantes, y sobre todo, la reproducción de esta capa obrera.

\section{Materiales y miradas}

El trabajo rural migrante estacional ha sido abordado profusamente en la literatura y la sociología regional o laboral de comienzos del siglo XX (entre otros, Bialet Massé 2010 [1904]; Niklison 1915; Abregú Virreira 1917; Canal Feijóo 2010 [1948]) e investigaciones recientes (entre muchos otros Biaggi et al. 2007; Desalvo 2009, 2013; Neiman 2009; Ledesma y Tasso 2011, Tasso y Zurita 2013). Santiago del Estero posee una intensa historia de migración laboral (y de expulsión poblacional) que se remonta a los tiempos coloniales (Farberman 1998). Desde la década de 70 del siglo XX el capital agrario pampeano requirió fuerza de trabajo con experiencia en procesos laborales previos, que en los obreros santiagueños se caracterizaba por migraciones al algodón en Chaco y la caña de azúcar en Tucumán. Este tipo de trabajo se compone de bajos salarios y críticas condiciones laborales (con excepciones de mejoras en la infraestructura en determinados campamentos), pero la brecha entre el salario obrero y la plusvalía obtenida por la productividad del trabajo mismo es gigantesca: dependiendo de la variedad lograda en laboratorios, cada grano de calidad premium puede llegar a cotizarse 
en varios dólares. El ingreso extrapredial del obrero a la economía familiar adquiere porcentajes muy altos respecto de ingresos por explotaciones agropecuarias (EAPs) familiares, en el orden del $70 \%$ y puede llegar hasta el $100 \%$, con lo cual toda la literatura campesinista que refiere a estas poblaciones rurales es problematizada (cf. Desalvo 2016). Es fundamental consignar un cruce de datos sociolingüísticos: dependiendo la demanda de cada año, el sector poblacional aludido se compone de entre 35.000 hasta picos de 50.000 obreros de la mesopotamia provincial (Neiman 2009; Ledesma y Tasso 2011; Desalvo 2013). La gran mayoría de esos obreros proviene de los departamentos Figueroa, Salavina, San Martín, Atamisqui y Sarmiento (Ledesma y Tasso 2011). A su vez pertenecen al núcleo de departamentos con más proporción estimada de población bilingüe quichua-castellano, según las estimaciones actualizadas de Albarracín (2016: 304): Figueroa con 80\% (14.256 habitantes); Salavina con 80\% (8.974 habs.); San Martín con $70 \%$ (6.882 habs.); Atamisqui con 70\% (7.646 habs.) y Sarmiento con $70 \%$ (3.225 habs.). El total estimado 4 (sumando a otros departamentos de menor incidencia bilingüe) es de 150.600 hablantes bilingües solo en Santiago del Estero. Esto connota un dato jamás postulado en estudios previos: el modo como en las últimas décadas la población bilingüe quichua-castellano pasó a consolidarse como capa significativa del ejército de reserva del capital.

El proceso de trabajo de la desflorada (despanojamiento) de maíz transgénico, se compone de cuadrillas. Cada integrante toma un surco, extrae la flor a la planta denominada "hembra" para que otra variedad denominada "macho" la polinice. Si la "hembra" llegara a autopolinizarse o a otras "hembras", el lote se "contamina" y el maíz producido no es el híbrido requerido por la empresa, con lo cual esa porción de lote se pierde: por eso es tan importante "saber desflorar" y no ser "chalero" (que deja flores). Se tarda entre 1 y 3 horas en recorrer cada surco, a veces de 1,5 o $2 \mathrm{~km}$ de extensión. Al llegar a la cabecera, la cuadrilla descansa 10 o 15 minutos, y luego cada obrero retoma por un surco asignado numéricamente y realiza la misma operación. Mientras esperan que en un campo determinado aparezcan las flores que no han nacido aún, los peones toman otro predio. Son los ingenieros los encargados de indicar que la actividad ha finalizado. Una vez que finalizan, los peones deben limpiar el campo. Es decir, quitar los yuyos que estorbarían la tarea o las llamadas plantas de crecimiento anormal denominadas "fuera de tipo" (Desalvo 2009: 131-132). Dependiendo de la

\footnotetext{
4 Son valores estimados porque no hay indicadores censales destinados exclusivamente a la lengua (Albarracín, 2016). En $\mathrm{SdE}$, no hay una vinculación directa entre etnia y lengua, sino un conglomerado étnico (indígenas, árabes, criollos, afrodescendientes, europeos, etc.) devenidos bilingües quichua-castellano, cuyo proceso de conformación (como bilingüismo) habría surgido a mediados del siglo XIX (Grosso, 2008). Debemos agregar un número similar de bilingües repartidos en el conurbano bonaerense (Albarracín 2016).
}

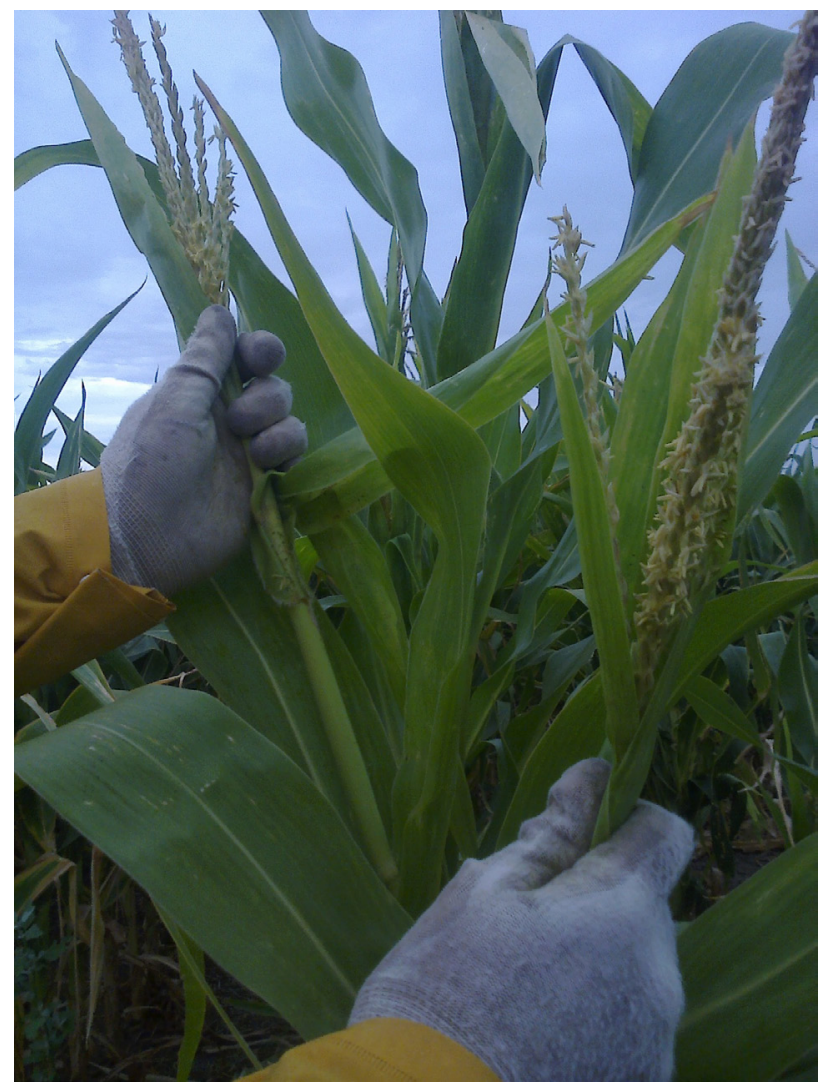

Figura 1: Modo de despanojamiento de la planta de maíz (foto del autor)

Figure 1: Mode of detasseling of the corn plant (photo by the author)

variedad aplicada, las plantas pueden ser de 1,50 m. - llegar hasta los $3 \mathrm{~m}$. (numerosas variedades del tipo Hércules o Pucará) con diferentes rangos de dureza de la hoja, situación que es temida por muchos obreros por las dificultades del despanojamiento y el dolor corporal que este provoca.

Los estudios sociolingüísticos suelen enfocarse principalmente en usos provenientes del habla y las interacciones cara-cara, dependiendo de las diferentes metodologías "clásicas" (Garfinkel 1968; Gumperz y Hymes (2002) [1972]; Gumperz 1982, Sacks et al. 1974). En un marco de interacciones en lenguas nativas en registro escrito, son escasas las investigaciones sobre usos de lenguas nativas en redes sociales, puesto que se trata de un fenómeno muy reciente (Cunliffe et al. 2013; Cru 2014; Jones 2015; Unamuno y Ballena 2017). Desde la sociolingüística interaccional hace cinco décadas se intenta profundizar sobre aquello que los hablantes hacen con las lenguas. Gumperz y Hymes (1972) postularon el concepto de repertorio como el conjunto de recursos a disposición de las personas para actuar socialmente. Dada la enorme utilidad pero también la generalidad del concepto, lo restringimos a su aspecto interaccional: 
nos preguntamos qué motiva a que un grupo de obreros despliegue un determinado repertorio en sus interacciones virtuales. Estos repertorios se componen no solo de formas lingüísticas y configuraciones semánticas y pragmáticas para producir e interpretar significados situados y sociales, sino que incluye "formas de expresión multimodales incardinadas en el discurso" (Mondada 2004) y culturalmente reconocibles en ciertas capas/ franjas de la comunidad.

Si bien el registro expuesto mostrará que los recursos lingüísticos se están reorganizando incesantemente por su puesta desplegada en el juego de la interacción (Mondada 2004; Nussbaum 2012), este artículo aporta en un aspecto no siempre trabajado: aunque la sociolingüística ha demostrado la existencia de dicha dinámica (la reorganización incesante del repertorio bi o plurilingüe), no profundiza las causas efectivas que la motivan. Sin pretender una sistematización general, aquí la propuesta metodológica específica es intentar captar etnográficamente la vinculación intrínseca entre trama sociolaboral e indicios interaccionales. Describiremos dos casos específicos de usos bilingües en el chat virtual, pero la dinámica sociolingüística que analizaremos se reproduce en una capa conformada por decenas de miles de obreros bilingües, ubicados en la mesopotamia santiagueña.

\section{Caso 1: "Nos han hecho akachir"}

Al no ser pariente, vecino o conocido de la zona, es imposible ingresar a una cuadrilla pues se buscan obreros experimentados para un trabajo caracterizado por la fuerza, la rapidez y hasta la fineza en el procedimiento manual de despanojado (dependiendo la variedad de planta y el requerimiento de cada empresa). El problema del rendimiento no solo es privativo de los novatos: Don Braulio (que tenía 20 años de desflorador y 20 años anteriores de trabajo ininterrumpido con el hacha) quedó internado una semana en un hospital por pisar uno de los miles de pozos de mulitas en medio del surco. Estaba casi deprimido mientras miraba su tobillo torcido e irremediablemente hinchado. No se trata de un ambiente de trabajo "esclavo" (como suele declamarse en innumerables notas periodísticas) sino que está atravesado implícitamente por un intenso miedo moral por posibles "fallas": accidentes que perjudican el rendimiento de la cuadrilla en el surco, cuya baja categorización otorgada por la empresa (incluso para el año siguiente) podría comprometer seriamente la subsistencia de muchas familias. Por eso me llevó tres años lograr ingresar. El cabecilla inspeccionó mis manos ásperas (que previamente preparé así) para evaluar mi ingreso en la cuadrilla. Son numerosos los accidentes laborales: "puntazos" en la espalda, dolor en las manos y las piernas, numerosas torceduras, heridas en las manos por cortes con la hoja de maíz, la "maldejada" (retención muy dolorosa del orín), diarreas, vómitos; fisuras y fracturas en los tobillos por los ya mencionados pozos de mulitas, o la "muñequiada" (frecuente torcedura de muñeca). Todos conocen a algunos de la zona que murieron en el surco, principalmente por causas cardíacas y por Chagas.

Por todo esto, en los comentarios del próximo fragmento ${ }^{5}$ el rendimiento laboral era el tema predilecto para interactuar en quichua. Pedro estaba contando a sus amigos de Pergamino y Córdoba (desfloradores bilingües de su zona que estaban trabajando para otras empresas en la pampa húmeda) cómo habíamos sentido ese día el dolor del cuerpo y la extenuación por despanojar plantas de una variedad "dura" (pucará) de gran altura. El modo como exponemos el diálogo es complejo (describimos una interacción virtual pero estamos presentes en el espacio físico de uno de los usuarios, Pedro), de modo que pedimos al lector un esfuerzo para seguir la estructuración del episodio experimentado.

\section{Campamento (sur de Buenos Aires)}

1. Pedro: [nos enseña cómo funciona la App] a mí me llegan así los mensajes, TODOS LOS días, de ellos [de otros desfloradores]. Yo estoy en un grupo. Yo les contaba que estaba aquí <8> bueno || ahora les voy a poner [escribir] que estamos bien, que estamos aquí también

"no-so-tross-ta-m-bien-con-un-p-ie-en | elestribo-peero-hoy-nos-han-he-cho-aka-chir-las-puca-rá"

[deletrea leyéndonos y teclea: "Nosotros bien con un pie en el estribo, pero hoy nos han hecho cagar las pucará"]

3. Pedro: [exclama sorprendido por el mensaje de José] mirá | en quichua JoseCITO/

5. Pedro [lee en voz alta su respuesta a Ramiro, para nosotros]. ANCHA UKU YUyas MANA atinku compañeroyshta (muy recuerdo que ya no podemos con el cuerpo compañeros) ${ }^{6}$

[nos comenta que] le he puesto [a Ramiro] | que [nos están] desflorando mucho el agujero ${ }^{7}$ | no pueden ya nuestros compañeros \|| le pongo

\section{6. [RISAS de todos]}

\section{Otros campamentos de desfloradores}

\footnotetext{
${ }^{5}$ Este fragmento proviene de un trabajo anterior (Andreani 2016a) cuya exposición servía solo como mera ejemplificación de un uso de celular dentro de la trama laboral. Aquí reanalizamos sustancialmente dicho evento interaccional para ver qué significa la membresía masculina/proletarizada dentro de la interacción bilingüe virtual. Adaptamos la lista de convenciones de transcripción en Tusón Valls (2002): negrita: discurso quichua; (paréntesis): nuestra traducción; / \ secuencias tonales ascendente y descendente; pausas: | breve, || media, <4> en segundos; MAYUSC: intensidad fuerte; ( ): traducción aproximada; [texto]: comentarios del analista; T (turno) o Ts (turnos de habla).

${ }^{6}$ Esta traducción no es literal, solo aproximada.

7 Se refiere a la explotación laboral.
} 
2. José [escribe desde Córdoba]. Jueves na puntiasqayku paguyman (el jueves iremos punteando para nuestro pago)-

4. Ramiro [escribe desde Pergamino, Buenos Aires]: Ahora andamos matando el segundo lote || con DOS surcos waay ${ }^{8}$ en dos días le entra la máquina al lote [Pedro nos lee el mensaje de Ramiro]

\section{[Samito y Remo se miran extrañados mientras Pedro lee]}

Había sido un día muy extenuante, y los novatos intentaban alcanzar tortuosamente el ritmo de los demás. Sin embargo Remo y Samito dijeron que no era cierto el mensaje "ya no podemos con el cuerpo" (T5). Pedro tenía 15 años de experiencia, al igual que varios de sus compañeros. ¿Qué había sucedido para que les llamara la atención y desaprobaran el mensaje que Pedro escribiera a su amigo "nos-han-he-cho-aka-chir-las-puca-rá" [nos han hecho cagar las pucará" y que "ya no podemos con el cuerpo"]? Ese mismo día, mientras estábamos en ronda de mate a las 20 hs (horas antes del chat), ocurrió una burla amistosa de Vera a Pedro, caracterizándolo jocosamente como un caballo pashuku. Pedro omitió referir esa burla en el chat de What's App a sus amigos desflorando en Córdoba y Pergamino. Todo tenía su origen en un suceso indebido, ocurrido tres días antes. A continuación reconstruimos el contexto de situación, para comprender por qué el rendimiento laboral termina configurando los sentidos de masculinidad en una dirección específica:

(...) El punto es que se pusieron a hablar de corridas, a ver si quién era más rápido. Empezaron a ver quién iba a correr. Lifo y Pedro se increparon mutuamente, Pedro no quería correr pero estaba "cebado" en que quería competir en alguna cosa con Lifo (es decir, "ganarle" en algo). El problema con Lifo es que se "coló" a la salida con nosotros, pero el grupo no quería llevarlo porque es un poco el aguafiestas. No les gusta su actitud altanera y fanfarrona. Hay algo con Lifo que no gusta al pequeño grupo donde estoy, y esto es interesante para analizar después en la moral (laboral) del grupo (sucede que Lifo quiere -de algún modo- mostrar su hombría frente al grupo, lo cual refuerza mi hipótesis central sobre esta masculinidad laboral). Pedro decidió aceptar la "competencia" con Lifo. Volo se preparó para filmar todo con su celular precario. El camino estaba libre, y solo había yuyos y cercos a los costados. Pero había algo más en el camino: piedras del ripio. Hicieron la

\footnotetext{
8 "Mi hijo", denominación afectuosa a su amigo Pedro
}

largada, y a los 30 metros de salir corriendo, Pedro - que usaba alpargatas y Lifo zapatillas- se cayó y se golpeó la rodilla contra una pequeña piedra -repito, era ripio-, con una lastimadura evidente por el golpe seco y puntiagudo en el medio de la rótula. "Uy boludo" dijeron los demás. Queriendo competir con Lifo, se había lastimado la rodilla -estábamos recién en el tercer día de comenzar la campaña-. Las carcajadas de todos se mezclaban con la burla, mientras se acercaban a Pedro para ver si estaba bien de su rodilla.

Cuando llegamos al campamento, Pedro intentó caminar de modo normal, y entró mudo a la pieza. Había pedido al resto de los changos ${ }^{9}$ que por favor no dijeran ni una palabra el resto de la cuadrilla. Por desgracia, dos días después (contando desde el día de su golpe) esa rodilla estaba muy hinchada, y Pedro rengueaba visiblemente dolorido en el trabajo del surco. Ahí fue que surgió una anécdota central en esos días: don Andy comenzó a referir de modo gracioso una anécdota sobre un caballo de carrera que Pedro había ayudado a criar, allá en Llaqta Sur. "Wayra Muyoq"10 fue el único caballo de carrera que tuvieron en la familia, y le había sucedido algo muy trágico y gracioso (para los demás): la radio anunciaba que Wayra Muyoq iba a competir con otro caballo muy bueno de otra zona, y los vecinos estaban muy expectantes. Pedro había ido a la radio para hablar acerca de su caballo, promocionándolo constantemente y arengando a todo el pueblo para que asistiera. Cuando había llegado el día de la carrera, el caballo se escapó hasta el río, se puso a tomar agua descontroladamente, y de repente cayó muerto sobre la costa, con la panza hinchada de agua.

En esa tercera noche (20 h) desde su golpe en la rodilla, estábamos hablando de comidas en la pieza, y entró Vera, que no es de nuestra pieza pero de vez en cuando se acercaba para hablar "macanas":

Pedro: A mí me encanta la morcilla ${ }^{11}$

Vera: ¿Te gusta la morcillita?

Pedro. Me encanta, yanasu, ancha gustaan ["amigo, muy me gusta", le contesta deliberadamente, para que Vera complete su

\footnotetext{
${ }^{9}$ Categoría nativa para referirse a muchachos.

10 En quichua, "remolino" (Wayra: viento; muyoq: que gira).

11 Este diálogo aparece muy sintético en un trabajo anterior (Andreani 2016a), que servía como ejemplo de situación de picardía masculina. Aquí es notablemente desarrollado y extendido con fines muy diferentes, porque permite reconstruir todo un contexto de situación que es clave para el tema propuesto.
} 
broma]

Vera: Con razón andas pashuku (MUCHAS RISAS de todos)

La burla había sido disparada. Pashuku es el caballo "de paso", un caballo que no corre sino que solo camina y por esa poca actividad desarrolla una panza prominente. Aquí el pashuku no solo era en referencia a un caballo sino a un hombre con la panza engordada con morcilla (de ahí la broma: de tanto "tragar penes" de otros). Las burlas de los vecinos amigos de Pedro en ese momento, referían que Wayra Muyoq, el pobre caballo "había dejado de ser de carrera, y al final [cuando murió] había quedado pashuku", es decir, como un caballo de andar lento y panzón. Es por eso que haberle dicho pashuku a Pedro, contenía tanta gracia para los puebleros de la cuadrilla que lo conocen (y cuyo triste final del pobre caballo era harto conocido por ellos).

Pero hay más, en relación con nuestro tema: aquí el pashuku es la oposición absoluta a la rapidez que representa un buen desflorador, a la "falla" de Pedro en haber jugado a la carrerita, en haberse caído y golpeado, y así faltar al rendimiento de la cuadrilla. La burla cobra su sentido intenso de humor, que solamente este contexto lo hacía posible.

Ese suceso había servido para que -a partir de ahora- don Andy comenzara a preguntar: "Che ¿qué dice que le ha pasao a Wayra Muyoq?" La referencia al malogrado caballo generaba enormes carcajadas a los changos. Le estaban tomando el pelo (mofándose) al pobre Pedro, con su rodilla hinchada, y caracterizado como el Wayra Muyoq que había caído muerto con la panza llena de agua. Pero en un momento de la risa y por su caracterización de la escena del caballo muerto, Don Andy cambió notoriamente de actitud y se puso serio: "che, así que había caído el caballo de don Segundo [papá de Pedro] ¿no?". Yo no entendía por qué había modificado su comentario: era muy evidente para los demás que lo hizo para no generar sospechas al capataz de la empresa, quien acababa de pasar al costado del grupo (detrás de don Andy) y muchos de nosotros no habíamos reparado en su presencia.

El humor de don Andy escondía otra cosa: que no había que "hacerse" el corredor, no había que lastimarse ni golpearse. El humor de don Andy reflejaba todo aquello que se debía cuidar y desarrollar: el rendimiento como desflorador. Esas referencias chistosas son un modo interno de control en la cuadrilla. Por eso Pedro no quiso decir nada a nadie, hasta que le dolió demasiado y no pudo ocultarlo más. Por eso la referencia al Wayra Muyoq, como cargada (burla) a Pedro.

Durante esos días, el miedo de Pedro a fallar con su rodilla era enorme. Estaba muy preocupado porque fumaba más cigarrillos que de costumbre, por la culpa. Pedro me decía que sentía que era una falta de respeto a la cuadrilla (cuaderno de campo).

Precisamente, al tercer día de este accidente y con la pierna visiblemente hinchada, Pedro estaba enviando el mensaje de Guasá expuesto anteriormente, omitiendo el accidente de la rodilla a sus amigos desfloradores en Pergamino y Córdoba. Si bien la jornada fue extenuante, Remo y Samito (por saberse "aguantadores") no se sentían para nada aludidos cuando Pedro escribía en nombre de todos que "ya no podemos con el cuerpo". La explicación de todo estaba en el accidente sufrido por Pedro, cuyas jornadas extenuantes perjudicaron aún más esa rodilla golpeada. Cuando él escribía "nos-hanhe-cho-aka-chir-las-puca-rá", no solo estaba el problema del rendimiento, sino también la culpa, la "condena" simbólica (y jocosa) de su cuadrilla, la amenaza de despido, y simultáneamente la falla en la masculinidad por una imagen negativa de "no ser un buen desflorador".

\section{Caso 2: Imat kan cha validación de imagen?}

Esta comunicación es del período 2013-2014. El extenso fragmento $^{12}$ pertenece al grupo de chat, dos meses después de que volvimos de la "campaña". Este grupo virtual se fue armando lentamente, conforme los changos iban adquiriendo gradualmente los dispositivos Androids. Se trata de un grupo que entre 2014-2016 fue alternando entre 30 y 45 usuarios. Las "picardías", las burlas, los cambios temáticos en quichua, y sobre todo la circulación de información muy específica sobre determinadas gestiones laborales, nos permiten adelantar que estos usos de What's App no están atravesados por aspectos tradicionales, familiares y mucho menos "ancestrales". Alternamos el análisis junto con cada progresión del discurso de chat. No elaboramos cuantificaciones de usos quichuas en un registro casi "total" de esta red social, sino que buscamos comprender las definiciones en las que tienen lugar esas interacciones (Hymes, 2002 [1972]):

\footnotetext{
12 En el análisis, usamos T (turno) o Ts (turnos). Los fragmentos de interacciones, se exponen del siguiente modo: 19- Tincho: Maiman. Caiman o santiaguman? > escritura del usuario, sin normalizar (Mayman? Kayman o Santiaguman?) > escritura quichua normalizada[¿A dónde? ¿Para aquí o a Santiago Capital?] > traducción aproximada [se dirige a Pablo] > interpretación propia, reparación o rellenado de la frase
} 
1- Chiri: Entonces tiene que tener o estar en anses keno!??? Hay hay pedir te dan la sabana de aporte del hombre digo yo creo que es haci che 2- Rengo: Yo tengo un contacto en la AFIP!!! puedo averiguar, necesito los datos. Obvio!!

3- Caspito: Ha si seguro hay el amigo Tincho te da dar los datos

4- Rengo: Me kedo sin batería. Igual a la noche veo.

5- Yo: [había una pregunta de Caspito del día anterior "I ke le pasó a don Andito?" en referencia a que no lo dejaron viajar con su cuadrilla habitual] Lo de don Andy es un caso de los viejos que no pueden hacer determinados trámites. Supongo que habrá muchisimos casos de viejos asi... es triste el asunto che

6- Rengo: Miren est video!!!! [un chiste de Pochi Chávez, un humorista local]

Quiero opiniones...

7- Pablo: Es fácil solicitale vos Tincho que tenes acceso a la tecnología [no puede ver videos en su dispositivo]

8- Tincho: En anses podes saca tu clave personal en la cual ingresas con tu cuil y ahí te figuran todos tus aportes es fácil y muy práctica a

9- Chiri: Aja, pasa q le averiguamos en anses con la gente de Oficina Estatal ${ }^{13}$ pero nose q paso. Es a nivel empresa la cosa.

Parece q van a empezar a ralear a la gente $q$ tiene muchos aportes [se profundiza ese saber entre ellos]

10- Tincho: Algo de eso entendi

11- Pablo: Mmm ... Ah ósea no tiene nada q ver q no tenga libreta o aportes sino q la empresa no lo kiere llevar, como a don Andito [el caso que yo referí en L5]

12- Rengo: Q lastima che

IO ando con Monsanto redujeron el sueldo pero te atienden bien [comienzan a hablar del trato de las empresas, tema de frecuencia reciente]

Che la verdad

Gumperz (1982) apuntaba que en su momento faltaban herramientas de registro más eficaces que pudieran "captar" de mejor modo las pistas en las interacciones, pero enfatizaba en lo importante de sostenerse en un "background etnográfico" para comprenderlas (cf. Duranti 2000: 127). Antes de comunicarse mediante la App para intercambiar información relevante, los muchachos utilizaban el espacio de bailes, reuniones, eventos folklóricos, actos escolares o los infaltables campeonatos de fútbol (a la madrugada), con el fin de intercambiar información vital para sus intereses como obreros. La progresión temática del fragmento indica cómo entre ellos efectivamente explicitan y profundizan

\footnotetext{
13 Modificamos el nombre de la dependencia estatal real.
}

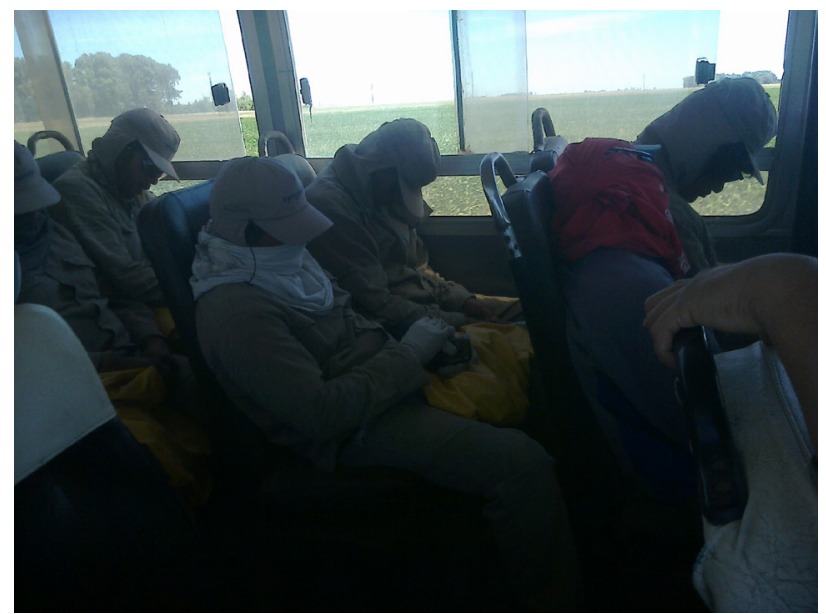

Figura 2: Extenuación de la cuadrilla al volver de una jornada de 13 horas continuas (foto del autor)

Figure 2: Exhaustion of the crew's workers, upon returning from a continuous 13-hour shift (photo by the author)

sus procedimientos sobre trámites (Ts 7-11). Desde hace pocos años, los desfloradores están compartiendo diversas informaciones, y mientras lo hacen, están haciendo otras actividades que superan al mero aspecto lúdico (el video de un humorista santiagueño, en T 6), incluso entre muchachos que jamás podrían verse en bailes o eventos religiosos, por la enorme distancia geográfica. Ese video era uno de muchísimos que se compartían (como es usual al compartir archivos de videos o audios en What's App), pero aquí cobraba un rol singular, y estratégico en términos de adquirir reconocimiento en la sociabilidad masculina: ellos acumulaban estos archivos como reserva narrativa humorística que servía después para compartir en cualquier ambiente con otros muchachos y adultos provenientes de esa membresía migrante (momentos breves de descanso al costado del lote, comedor y cocina, dormitorios del campamento de trabajo), y membresía posteriormente proyectada y reproducida en sus zonas (bailes, patios, "tomaciones"14, especialmente como asistentes silenciosos de actos culturales, etc.). Aunque "la quichua" no aparece en estos videos, los cuentos son narrados ya fuera del chat, y dicha lengua emerge gradualmente en el repertorio narrativo cara-cara, hasta convertirse en discurso dominante mientras prosigue la retahíla de chistes y cuentos.

13- Tincho: Si, hay q armar algo changos. Un gremio de desfloradores, no hay nada

komo puede ser q nunca sabemos cuanto ganaremos y aun abiendo cumplido contrato

tenemos q andar como bola sin manija por mucho tiempo

Hasta q nos llevan a cobrar

14- Antuco: Mira yo tenía contrato con la última

\footnotetext{
14 Eventos informales para beber cerveza o vino
} 
empresa desde el 27 de diciembre hasta el 27 de febrero y me largaron una semana antes del contrato. $Y$ en el contrato o papel del sueldo decía queda sesante de trabajo ! Yo creo que ellos tendrían que respetar mi contrato. Yo vine como si fuese que vengo avandonando, ellos me largaron eso fue

15- Rengo: Y habrás abandonado vos hecho el guapituuu [guapo]

16- Chiri: Jajaja

17- Antuco: No papi yo reclame antes de cobrar y me dijeron vete a Oficina Estatal y pregunta esta agenda contrato que les isims [hicimos]

18- Remo: Yo tambien voy a ir [a la Oficina Estatal]

19- Tincho: Maiman. Caiman o santiaguman?

(Mayman? Kayman o Santiaguman?)

[¿A dónde? ¿Para aquí o a Santiago

Capital?]

Si bien las posibilidades de una agremiación independiente del sindicato oficial es imposible, nótese que comienzan a plantear algo que va más allá de lo que conocen como el único gremio conocido (T13), cuyo carácter burocrático jamás les ha proporcionado ayuda alguna. Emergieron datos importantes para que los demás compañeros estuvieran atentos: Antuco recoge el guante de Tincho, narrando sobre la liquidación y emisión el recibo estando "presentes" en el campamento (T14). Como respuesta negativa a esta narración, surge la caracterización irónica del rendimiento de Antuco (guapituuu), que es lo opuesto al reclamo laboral "agremiado" que Tincho estaba proponiendo: aquí el Rengo se burla de las capacidades de trabajador de Antuco (T15). Pero nótese que Tincho cambia el código a quichua (T19), y es información importante: se trata de conocer la ubicación de su amigo para que lo ayude en el trámite. Tincho es, evidentemente, el único de todo el grupo que apela al quichua para otorgar más credibilidad a un argumento demasiado impensable al grupo, como es intentar una agremiación por fuera de UATRE. Pero Antuco y Rengo aprovechan el cambio de código propuesto por Tincho (castellano a quichua) pero para instalar otro tema, esta vez con picardía y casi fusionado al sensorium masculino:

20- Antuco: Che ancha guarmis sumaj apinky imaina sutenk cha hermanas kanku konkarani

(Che ancha warmis sumag apinki. ¿Imayna sutenqa cha hermanas kanku? Qonqarani

[Che muchas mujeres lindas tienes vos ¿cómo se llaman las hermanas? Me olvidé] 21- Rengo: Adelaida kanqa [¿Adelaida será?] 22- Antuco: Apellido ?? Las hijas del músico hóm creo que son [volvió a castellano para manifestar duda]

23- Tincho: Ah. Ari. Com ninki zelman Sofian!! Caai chivu, imat rimallcan ca hombreee.
(Ah. Ari. Cómo ninki Zelmaan Sofíaan! Qaay chivu. Imat rimachkan ká hombree?)

[Ah. Sí. ¿Cómo dices, con la Zelma y con Sofía? Mirá, chivo. ¿Qué está hablando este hombreee?]

24- Gusti: La de don Mario Peralta q esta en bsas como se llama? [referencia a una muchacha]

25- Tincho: Hay unita muy linda en quebrachos o tako ${ }^{15}$ [provisión de información sexual fundamental para mantener el canal con los demás]

26- Gusti: Telma Alagastino sutin kan yanasu!!! [Telma Alagastino se llama, amigo] [vuelve al quichua para manifestar conocimiento ante todos, en una aclaración taxativa]

27- Antuco: No po hómb otro apellido tienen creo que son la hermana de la señora del hijo de Juanino Acosta

28- Rengo: Aaaaah!!! Ya se!!! Las tolozas!!

29- Antuco: Chai kumpa ancha sumitaj kanku kanchaina suj niara ancha sumaj kanky pero ancha guacho

(Chay cumpa ancha sumitaq kanku. Kan chayna. Suk niara "ancha sumaq kanki, pero ancha wakchu")

[Esas, compadre, muy lindas son. Es así. Una me dijo "muy lindo sos, pero también muy guacho"] [testimonio en primera persona con esa mujer, en quichua, obviamente con picardía]

30- Gusti: Mana casucunaiki tian. Chaina seguisus purencancu chaimant, añacunaiki tian de vez en cuando. Jaja!!

(Mana kasukunayki tiyan. Chayna seguisus pureq kanku chaymant. Añakunayki tiyan de vez en cuando. Jaja!)

[No le tienes que hacer caso. Así después siguiéndote van a andar. Insultalas de vez en cuando. Jaja!!] [se pronuncia sobre cómo debería ser el trato con mujeres, según su perspectiva]

31- Antuco: Ja ja ja

32- Chiri: Ari che chaina niara pai munan kosa ceria noka mana po

(Ari che, chayna niara pay munan qosa seria, noqa mana po)

[Sí, che, así me decía, ella quiere un marido serio, yo no, pues]

33- Pedro: Pa muy yuya ese Chiri [Ehh, muy mentiroso ese Chiri]

No I creas nada vos

Mientras Tincho enseñaba a usar la aplicación a sus compañeros (en el descanso de la noche, y en el ambiente de la pieza se contaban cuentos "picantes" y anécdotas

\footnotetext{
15 Son pequeños parajes que llevan topónimos de árboles de la zona.
} 
sexuales sobre experiencias con muchachas de sus zonas), Pedro aprovechaba para enviar lúdicamente mensajes en quichua a otros compañeros de otras zonas de la pampa húmeda (como el primer registro de chat del caso 1). Estas manifestaciones de saberes sexuales sobre muchachas, permiten explicitar los gustos sexuales de estos obreros, y la mirada que portan sobre las relaciones de pareja. Pero estos temas no habilitan a cualquier participante. El grupo de chat se caracteriza por un detalle especial de membresía: ser "desflorador" es haber pasado una prueba implícita de ser buen "rendidor", una "máquina". Dicha membresía es implícita, pero permite comprender cómo ellos socializan intensamente en otros contextos fuera del trabajo migrante, sobre todo bailes y boliches con gran asistencia de mujeres adolescentes y adultas jóvenes. Por eso se trata de un "ingreso" extremadamente restrictivo a la trama labora. No cualquiera puede ingresar a una cuadrilla: el rendimiento laboral de cada uno de los miembros determina notoriamente el puntaje que la empresa semillera otorgará a la cuadrilla. Eso motiva que los miembros sean conocidos o insertos en una misma red familiar, vecinal o zonal, pero siempre bajo el criterio de ser "buenos desfloradores" o "máquinas". Es prácticamente imposible que compartan información sexual sobre muchachas de la zona (Ts 20-32) si no pasaron por esta instancia previa de masculinización proletarizada. La clave de todo este proceso es el "rendimiento laboral": mediante trabajo de campo realizado en sus comunidades, confirmamos que esa configuración de masculinidad es determinante para reproducirla posteriormente en sus zonas, porque las relaciones cotidianas (sobremesas familiares, "juntadas" alcohólicas en las casas, reuniones en bailes, etc.) se nutren de esos dispositivos de masculinización surgidos en la trama laboral migrante. La membresía se acredita por haber "sufrido" como los demás, pero sobre todo por lograr mejorar el propio rendimiento y no retrasar el ritmo de desflore a la propia cuadrilla. Esa "superación" por la vía del rendimiento permite ingresar a otros tipos de interacciones más "cómplices": chistes, referencias sexuales (Ts20-32), burlas, innumerables referencias burlescas al rendimiento (T15), además de desafíos de capacidades competitivas (tirar piedras, habilidades ecuestres, taba, cartas, fútbol, carreras, etc.). Es desde ese ambiente donde el quichua se despliega por ese camino angosto, después se ensancha y se hace más frecuente en interacciones más intensas. Esto último es muy importante, porque son las condiciones de producción del discurso quichua, mediante una dinámica social contextualizada que habilita la emergencia de una lengua específica, dentro de un repertorio dialogado. Sin embargo, Remo es quien decide no proseguir con la picardía sexual, porque retoma el tema del trámite en Ciudad Capital. Dada su manifiesta preocupación por estar "limpio" para la empresa (la cuadrilla saldrá en cuatro meses, su pareja está embarazada de su tercera hija y necesita el dinero), enfatiza con "he dicho":
34- Remo: e io voi mañana a la Oficina Estatal he dicho

Y ke más hago aya?

35- Tincho: Tu clav te sirv para que vos veas tus aportes

36- Caspito: Obtener cuil

Certificado de nagativa

Jubilación o pensión si tienes

Para cambiar tu boca de pago

37- Chiri: Nose xq te pide Oficina Estatal si eso es personal

38- Caspito: Bueno... Si vos tendrías q preguntar eso como arias? Capaz q yo entre en otra página...

39- Chiri: Pero ya generast tu clave vos?? O no podes

40- Remo: Para... Ahora m pide cuil... Fech nac y todo...y validación de imagen...

Imat can cha valid d imagen?

[cambia al

\section{quichua para expresar duda]}

(Imat kan cha validación de imagen?)

[¿Qué es esa validación de imagen?]

41- Chiri: Ahi te aparece un código ese copia y pone

42- Remo: El cuil o fecha d nac son inválidos.

O no concuerdan $\mathrm{m}$ dice... Pero yo I ingrese correctamente...

$\mathrm{Q}$ cagada mana vinut upiaj riini che (mana vinut upyaq rini, che)

\section{[distensión]}

[no voy a poder tomar vino che] Jajaja

43- Chiri: Eh si querés agregame en privado y pasamd [repara el tema]

44- Pedro: pásame Tus datos

IO tengo la makina aki de la empresa

y pruebo [tiene conexión a internet, "máquina" refiere a la página web de la Oficina Estatal]

45- Remo: Dale.

46- Chiri: Pasale tu cuil

Fecha de nacimiento

No se trata solo de nuevas gestiones ante el Estado. Los conocimientos de estos obreros sobre las propias empresas semilleras dan cuenta de una relación que ya lleva décadas. Remo, charlando en la pieza a la noche con los demás, manifestaba un conocimiento muy específico acerca del pasado de las empresas que los contrataban, y del modo como sus capitales se absorben y acumulan entre sí: "Dekalb era famosísima, después ha pasado a llamarse Monsanto, contratación directa hacían ellos de mano de obra... y Civa pasa a ser Syngenta". Tincho agregaba: "Pero en el 2000 más o menos aparecen otras contratistas, que son empresas administradoras como Adecco, CCT y otras como Manpower; esta contrataba para Monsanto, y Adecco para Syngenta". Ellos mismos reconocen que ese conocimiento se expandió 
notoriamente en los últimos 3 o 4 años mediante las redes virtuales, pero con un ambiente muy particular: como ambiente heterosexual, masculino, endógeno e intra-generacional. Pero en el T40 Remo usa el quichua como recurso para hacer explícita su desorientación total ante el trámite virtual de la "Oficina Estatal". Nótese que ese conocimiento específico (capacidad de evaluar a las empresas por el trato laboral, salario, condiciones de habitabilidad, estafas, ocultamiento de información, deslocalización del campamento para impedir la huida, etc.) en ningún momento permitió mejorar condiciones laborales de estos obreros. Dicho de otro modo: van desarrollando un conocimiento más elaborado sobre cómo quedar "limpios" del mejor modo posible ante la empresa, para que los empleen nuevamente, e incluso numerosas intervenciones sobre cómo son explotados, pero no pueden modificar objetivamente dicha situación. En el turno que sigue (47) Remo refiere la "mala suerte" por no poder realizar el trámite estatal vía internet, y es figurado como "agujero de la vulva".

47- Remo: Con celular no se puede. Yo intente el año pasado y nada. No podia terminar la operacion. Despues lei los comentarios y a todos les paso lo mismo

Aaaaaaaaaaaaa lakiap utkunnn ...

[agujero de la vulva]

[figurativo: mala suerte compartida entre varios] ${ }^{16}$

Ja ja

48- Chiri: Jajajajaj

49- Pedro: Despachituit? Caiiaaa

(Despachituyta? Qaya::)

[¿A mi despachito? Mañana] [después

de la risa, prosiguen en quichua]

50- Remo: Imajma yankainkiyapas niaiaaaaa ja ja..

(Imayna llamkankillapas niay á jaja)

[¿cómo? ¿vos también vas a trabajar?

Decíme jaja]

51- Remo: Chiri yo el mío y dl hombre lo ice con mi celu

Hay q actualizar el link no volver atrás $<2>$

52- Antuco: Asa q bueno chee.

Asado nian (asado me dice)

Asa asa [juega con el sonido de "asado"]. Zzz. Volviendo d pisar [pisar = copular]

53- Remo: Nis moño (diciendo "moño")

54- Cala: Che Umita cual es el paso de Miguel Yanacón??

El grupo de chat permitía circular información importante para llegar, en este caso, a la casa de Yanacón (T54): se trata de un trabajador "muy rendidor" para la

\footnotetext{
${ }^{16}$ Es muy frecuente escuchar, en todo el territorio provincial, una queja repentina como ¡Ay, laka! (vulva)
}

cuadrilla donde Cala es integrante (quien no es todavía el cabecilla porque le "faltan años de experiencia"). El objetivo era registrar a este señor Yanacón para la libreta del trabajador rural en la Oficina Estatal. Si bien el conocimiento territorial de cada uno de ellos es muy amplio, todavía hay desconocimiento para ciertas zonas que se tornan inaccesibles por lluvias. La vasta zona geográfica es homogénea en la composición del monte xerófilo (adaptado al calor y salitre imperantes), pero muy complicada en accesibilidad vial. Por ejemplo, Chiri es de Sabagasta; Rengo es Yacu Hurmana; Pedro es de Yana pozo; Tincho vive cerca de Llajta Sur; Remo vive en Herrera; Antuco vive en Icaño: la superficie que cubre los puntos geográficos (entre todos) es de más de 30.000 kilómetros cuadrados.

55- Umita: El q esta mas,al norte del, de don Uma Pogonza Rodríguez era, no pogonsa Justo donde Aces la curva de la casita q esta en la barranca de el río Pero cuanto más vete al privado y te digo En Yana Paso [un paraje cerca del río] 56- Cala: Cha "Charatita" [a Pedro] rikurin che [esa charatita ${ }^{17}$ aparece che]

57- Pedro (Charata): Yacut amun mishky mayupi way

(Yakut amun mishki mayupi, waay)

[viene agua en el río Dulce, hijo]

58- Umita: Asi??

59- Chiri: Q bueno che

60- Remo: Ace falta pa esa zona

Ama yuyapai Charata hu ancha yuya kai kumpa kam

(Ama llullapay, Charata, ancha llulla

kay cumpa qam)

[no mientas, Charata, es de mentiroso, sos cumpa]

61- Remo: Asi no te va dar trabajo Pedro, Rengo po

62- Pedro: Jaja

63- Remo: En seri amigo

64- Pedro: Llovio mucho al norte y desbarrancaron lindo en la orketa [una zona del río Dulce]

65- Rengo: Pedro no me quiere del todo po pobre Rengo!!!

66- Pedro: Jaja te pinto el gay jaja

[caracterización]

67- Antuco: Señor López tampoco me quiere dar laburo po, lo voy a correr del club ja ja [club donde Antuco es miembro de la comisión]

Mientras prosiguen con la progresión de información geográfica, manifiestan conocimiento cómplice en

\footnotetext{
17 Del quichua charata (ortalis canicollis, faisán americano).
} 
saberes de caza y pesca: la clave del ambiente, aunque no se note en el chat, es de matiz agonístico (desafío entre hombres para superarse en Ts 56, 60,64) con marcaciones homosexuales (T66). Pedro en esos años realizaba trabajo político para un candidato a comisionado municipal: esa sola acción generaba que Pedro fuera visto por los demás como alguien que ya no es "tan" obrero, sino alguien de una clase superior a ellos. Esto, por supuesto, no era cierto, pero la inteligencia y capacidad de gestiones de Pedro generaban en los demás esa percepción de clase. Por eso Rengo le exigía que lo ayudara a conseguir trabajo (Ts 61-63). Antuco, al igual que Remo, Tincho, Umita y Chiri, son activos miembros de las comisiones de los clubes infantiles de fútbol (T 67). Es un fuerte indicio de la participación de los jóvenes en la política pueblerina: en estos obreros, aunque traen ingresos para subsistir unos pocos meses, esa precaria movilidad social les permite valerse como actores determinantes para las comisiones de los clubes.

\section{Dinámica sociolingüística del proceso de trabajo}

Si retomamos la clásica dimensión austiniana de que decir es hacer, este tipo de interacciones virtuales permiten activar mejor otros saberes prácticos (relaciones con muchachas, trámites laborales en la Oficina Estatal, documentaciones varias, colaboraciones para que la información llegue a obreros que viven "dentro 'el monte") que los desfloradores hubieran realizado con muchísima dificultad en períodos anteriores al chat virtual. Pero esa nueva circulación de datos relevantes no les permitió modificar en su beneficio la intensa relación de explotación. Esa desazón (actualizada con anécdotas de estafas y liquidaciones de salario mal realizadas) es otro factor clave de la membresía referida: nótese que ya no es factor de masculinización sino de una siempre incipiente conciencia de clase.

Muchos de estos usos están motivados por varias cuestiones que se presentan aquí como inherentes:

a) se usa el quichua sin necesidad de manifestar su uso como demostración propiamente lingüística (como objetivación de la lengua en tanto objeto de intelección), sino por motivaciones laborales, administrativas o sexuales;

b) usan el quichua en referencias agonísticas (saberes de caza, pesca y habilidades rurales) para demostrar y mantener una conciencia implícita de "grupo" de muchachos pertenecientes a una zona compartida de la mesopotamia santiagueña;

c) hay perspectivas de masculinidad juvenil atravesadas por el proceso de explotación: este "ambiente de hombres" se compone de una historia "no dicha" (y no documentada) en estas interacciones, compuesta de muchos años de viajes y cuadrillas, en este caso la desflorada con casi medio siglo de proceso. Es una memoria compartida de gran extenuación y dolores del cuerpo, y consiguiente complicidad grupal a partir de

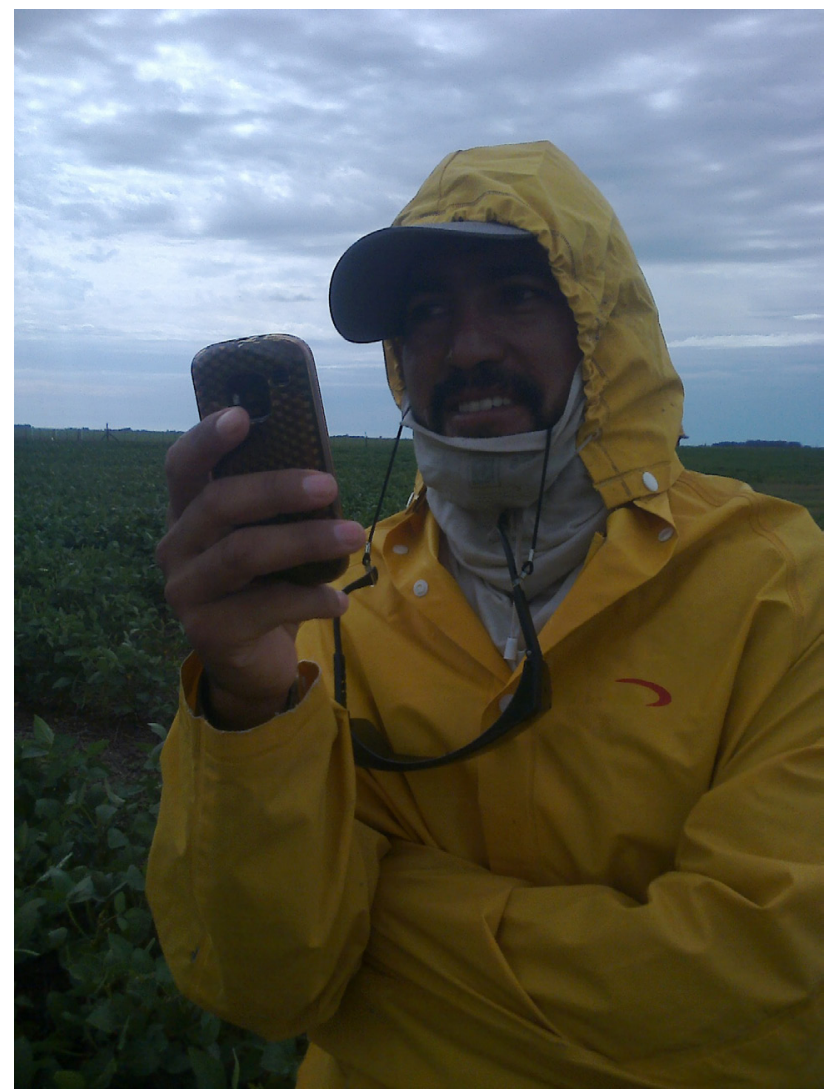

Figura 3: Obrero migrante probando por primera vez la aplicación de App en 2013 (foto del autor)

Figure 3: Migrant worker trying for the first time the application of What's App in 2013 (photo by the author)

esa "templanza" de hacerse "hombres" (como todo lo sucedido con la "burla" a Pedro en el caso 1);

d) esa zona compartida está mediada por una dimensión que se ubica a medio camino entre clase en sí (praxis laboral sin conciencia de clase) y clase para sí (solidaridad entre obreros rurales, a partir de una fluctuante conciencia de clase) puesto que mediante el chat virtual, pueden pueden conocer mejor las características de ciertos empleadores, condiciones de trabajo y formas de explotación que antes no conocían o no podían compartir (dadas las extremas distancias entre localidades de esta provincia).

Los casos descriptos de usos de chat no instauran nuevas formas de sociabilidad que permitan cierto "mantenimiento" del quichua (en tanto uso mediado por una nueva tecnología) sino que ya existe una dinámica social arraigada en el tiempo, pero actualizada bajo un soporte virtual. La clave del mantenimiento de "la quichua" en estas capas obreras no se motiva en el uso de un dispositivo móvil o un grupo de chat, sino que va en paralelo con la continuidad o transformación de los procesos productivos que los absorbieron como fuerza de 
trabajo (y su accesibilidad a recursos como el dispositivo móvil).

Tanto en el desarrollo del siglo XIX como la primera mitad del XX, los procesos locales de subsunción de trabajo por capital tuvieron como correlato (en zonas de baja productividad del trabajo) una muy escasa incidencia de la política lingüística dentro de los procesos de trabajo agrario estacional. La explotación de una fuerza de trabajo de escasísima calificación fue el tipo frecuente de demanda en los procesos productivos de diferentes períodos: a) expansión agrícola-ganadera a fines del siglo XIX; b) extracción de productos madereros en área forestal en la primera mitad del siglo XX; c) asentamientos poblacionales y posterior reutilización agropecuaria de muy baja productividad en zonas deforestadas desde mediados del siglo XX; d) auge del trabajo migrante estacional para multinacionales semilleras desde la década del 70 hasta hoy, absorbiendo obreros principalmente de la zona mesopotámica provincial. Esta situación no fue la misma que en zonas de capital desarrollado: tanto en el capital agrario como el industrial con baja productividad media (respecto del gran capital) los procesos inherentes de explotación de mano de obra más calificada generaron ámbitos de uso exclusivos en castellano para la gran mayoría de la población argentina.

Al haber sido un proceso con muy baja calificación que favorecía un tipo de aglomeración social (cuadrillas) cuya productividad del trabajo se aseguraba con obreros propios de una trama familiar/vecinal/zonal, "la quichua" era plausible de ser mantenida en interacciones cotidianas e inherentes a ese proceso laboral. La demanda de fuerza de trabajo en estos procesos productivos no precisó de una conversión lingüística-estatal completa (monolingües en castellano), sino que se delimitó al aumento de la productividad en función de la calificación que se iba aprendiendo en el proceso extractivo: tala, siembra, cosecha, despale, desenraizado, etc.

La trama socio-laboral nos está indicando algo aparentemente contradictorio: las condiciones de explotación en este tipo de trabajos, propios del capitalismo agrario desarrollado como el caso argentino, pero paradójicamente aplicado a una trama laboral de escasa incidencia de la política lingüística en castellano, pueden operar como (devienen un inesperado) factor de transmisión-mantenimiento de la lengua nativa como el quichua. Consideramos que puede aplicarse esta mirada a otras lenguas nativas ${ }^{18}$, para entender cómo determinados procesos de trabajo (y las transformaciones en la estructura productiva) que absorben grandes contingentes de obreros, pueden llegar a habilitar nuevos

\footnotetext{
${ }^{18}$ Esto es, en el supuesto de que contengan trabajadores migrantes, y con ciertas dinámicas internas de interacción social (cuadrillas de trabajo compuestas por familiares y vecinos) que impactan notoriamente en el "mantenimiento" de sus repertorios lingüísticos nativos.
}

usos o actualizaciones del repertorio lingüístico.

El quichua emerge en determinados ambientes de picardía, pero su ingreso en la interacción no se motiva desde la lengua misma. Los usuarios del chat intercambian información sobre el accionar sexual de muchachas (y de sus gustos como varones), se burlan entre sí con marcaciones homosexuales o de deficiencia laboral, discuten temas de política local, y sobre todo, intentan hacen circular datos fundamentales para realizar trámites estatales (libreta del obrero para el salario, entre otros), y sobre todo evitar (casi siempre sin éxito) ser estafados por estas semilleras multinacionales, o al menos lograr una precaria formalización en su relación laboral con la patronal. Describimos repertorios bilingües quichuacastellano donde se desarrollan nuevos conocimientos "administrativos", que antes eran exclusivos del reclutador (siempre un operador político de las localidades rurales donde viven estos muchachos). No se trata solamente del repertorio bilingüe desplegado en el chat, sino también un contexto de situación (reconstruido etnográficamente) al interior de la vida de la cuadrilla.

En este contexto y para el caso del quichua santiagueño, postulamos que estos aspectos permiten entender la dimensión de clase como configuradora y actualizadora de nuevos usos bilingües. Por fuera de cualquier discurso mayoritario (académico, ministerial, medial, educativo) que concibe el uso de la lengua nativa como sostenida en relaciones netamente familiares, entramada exclusivamente en el espacio folklórico, o las explicaciones que se limitan a eventos de socialización lingüística infantil de estos bilingües, aquí las motivaciones efectivas (y reactualizadas) de usos del quichua no son "folklóricas", "familiares" o "culturales", sino mediadas por un conocimiento "cómplice", masculinizado, adulto, lleno de picardías narrativas, en parte mediado por una red social virtual. Dicho de otro modo y evitando cualquier esquematismo economicista: no pueden comprenderse procesos culturales (lingüísticos) complejos sin observar su correlación con los modos de producción y de vida (cf. Marx, 1980 [1859]: 4-5) que ameritan ser descriptos y explicados en el escenario que les dan sentido.

\section{Agradecimientos}

Agradezco a Diego Albarracín y Florencia Paz Taboada, estudiantes que participan conmigo en dos proyectos PICT (2013-2283 y 2018-0706, dirección de Virginia Unamuno), quienes en 2016 realizaron la entrevista a Sebastián y me permitieron usar este decisivo fragmento para mi epígrafe. También agradezco a Mayra Juanatey por su lectura atenta, y a los evaluadores del arbitraje ciego del artículo, por sus observaciones precisas.

\section{Bibliografía}

Abregú Virreira, C. (1917). La vida del peón en los obrajes 
del Chaco santiagueño. Santiago del Estero: El autor.

Albarracín, L.I. (2016). La quichua. Ejercicios y gramática. Volumen III. Buenos Aires: Dunken.

Andreani, H. 2016a. Clase, masculinidad y lenguas en el trabajo migrante santiagueño. Signo y Seña, 29, 103-129.

Andreani, H. 2016b. La desesperación imperial de la burguesía provinciana. Apuntes sobre chovinismo historiográfico, lengua nativa y clase en Santiago del Estero (Argentina). Corpus. Archivos de alteridad americana, 6(1) ,1-23.

Biaggi, C., Canevari, C., Tasso, A. (2007). Mujeres que trabajan la tierra. Un estudio sobre las mujeres rurales en Argentina. Buenos Aires: Ministerio de Agricultura, Ganadería, Pesca y Alimentos.

Bialet Massé, J. (2010. [1904]). Informe sobre el estado de las clases obreras argentinas. La Plata: Ministerio de Trabajo de la Provincia de Buenos Aires.

Canal Feijóo, B. (2010. [1948]). Ensayos sobre cultura y territorio: de la estructura mediterránea. Teoría de la ciudad argentina. Buenos Aires: Universidad Nacional de Quilmes.

Codo, E., Patiño, A., Unamuno, V. (2012). Hacer sociolingüística con perspectiva etnográfica: retos y dilemas. Spanish in context, 9 (2), pp. 157-190.

Cru, J. (2014) Language revitalisation from the ground up: promoting Yucatec Maya on Facebook. Journal of Multilingual and Multicultural Development, pp. 1-14.

Cunliffe, D., Morris, D., y Prys, C. (2013). Investigating the Differential Use of Welsh in Young Speakers' Social Networks: A Comparison of Communication in Face-toFace Settings, in Electronic Texts and on Social Networking Sites. En: Jones, E. y Uribe-Jongbloed, E.. (eds.). Social Media and Minority Languages. Convergence and the Creative Industries. Bristol: Multilingual Matters.

Desalvo, A. (2009). Los obreros santiagueños en el desflore de maíz. Proceso y condiciones de trabajo. Anuario del Centro de Estudios e Investigaciones en Ciencias Sociales, 3(3), 129-148.

Desalvo, A. (2013). ¿Campesinos u obreros? Un estudio actual sobre la llamada población campesina de Santiago del Estero (2009-2012). Tesis doctoral en sociología. Universidad de Buenos Aires. Inédita.

Desalvo, A. (2016). Una aproximación a la naturaleza social de la población rural santiagueña: el caso de Salavina. Notas de población, 98,163-191.
Duranti, A. (2000). Antropología / ingüística. Madrid: Cambridge University Press.

Farberman, J. (1998). El peso de la continuidad. Tierra, trabajo familiar y migraciones en Santiago del Estero. Un estado de la cuestión. Población y Sociedad, 5, 165-186.

Garfinkel, H. (2006) [1968]. Estudios en etnometodología. Barcelona: Anthropos.

Grosso, J.L. (2008). Indios muertos, negros invisibles. Identidad, hegemonía y añoranza. Córdoba: Encuentro Grupo Editor.

Gumperz J., Hymes, D. (comps.). (1972). Direction in Sociolingüistics. Ethnography of communication, pp. 35-71. Nueva York: Holt, Rinehart and Winston.

Gumperz, J. (1982). Discourse Strategies. Cambridge: Cambridge University Press.

Heller, M. (2011). Critical ethnographic sociolinguistics. En: Heller, M. (Ed.), Paths to postnationalism. A critical ethnography of language and identity, pp. 31-50, Oxford: Oxford University Press.

Hymes, D. (2002 [1972]). Modelos de la interacción entre lenguaje y vida social. En: Golluscio, L. (Comp.). Etnografía del habla. Textos Fundacionales. Buenos Aires: EUDEBA.

Jones, A. (2015). Social Media for Informal Minority Language Learning: Exploring Welsh Learners' Practices. Journal of Interactive Media in Education, 7(1), 1-9.

Juárez de Paz, I. (1999). Lingüística regional Quichua Santiagueño-Español Argentino. Santiago del Estero: El Liberal.

Kabat, M. (2009). La sobrepoblación relativa. El aspecto menos conocido de la concepción marxista de la clase obrera. Anuario CEICS, 2, 109-128.

Marx, K. (1980 [1859]). Contribución a la Critica de la Economía Política. Madrid: Siglo XXI, pp.4-5

Ledesma, R; Tasso, A. (2011). Empleo rural y migrante estacional en Santiago del Estero. En: Ledesma, R; Paz, J; Tasso, A. Trabajo rural estacional de Santiago del Estero. Buenos Aires: Ministerio de Trabajo, Empleo y Seguridad Social-OIT

Mondada, L. (2004). Ways of 'Doing Being Plurilingual in International Work Meetings. En: Gardner R.; Wagner, J. (eds.), Second Language Conversations. Londres: Continuum.

Neiman, G. (2009). Estudio exploratorio y propuesta 
metodológica sobre trabajadores agrarios temporarios. Con la colaboración de Bachur, M. (MTESS) y Resa, A. (RENATRE) Ministerio de Economía y Producción, Secretaría de Agricultura Ganadería, Pesca y Alimentos. Proyecto de Desarrollo de Pequeños Productores Agropecuarios (PROINDER) Buenos Aires.

Niklison, J. E. (1915). Informe sobre las condiciones de vida y trabajo en los territorios federales de Chaco y Formosa, Boletín del Departamento Nacional del Trabajo, 32, Buenos Aires.

Nussbaum, L. (2012). De las lenguas en contacto al habla plurilingüe. En Unamuno, V.; Maldonado, Á. Prácticas y repertorios plurilingües en Argentina. Buenos Aires: Los autores. Grup de Recerca en Ensenyament i Interacció Plurilingües (GREIP).

Palermo, H. (2017). La producción de la masculinidad en los trabajadores del petróleo. Buenos Aires: Biblos.

Sacks, O; Schegloff, E., Jefferson, G. (1974). A Simplest Systematics for the Organization of Turn-Taking for Conversation. Language, 50, 696-735.

Tasso, A., Zurita C. (2013). "Aves de paso. Los trabajadores estacionales de Santiago del Estero". Trabajo y Sociedad, 21, 33-47.

Tusón Valls, A. (2002). "En análisis de la conversación: entre la estructura y el sentido. Estudios de sociolingüística, 3(1), 133-153

Voloshinov, V N. (1992). El marxismo y la filosofía del lenguaje. Los principales problemas del método sociológico en la ciencia del lenguaje. Madrid: Alianza Editorial. 